\title{
Proposal To Reclassify Leuconostoc oenos as Oenococcus oeni [corrig.] gen. nov., comb. nov.
}

\author{
L. M. T. DICKS, ${ }^{1 *}$ F. DELLAGLIO, ${ }^{2}$ AND M. D. COLLINS ${ }^{3}$
}

Department of Microbiology, University of Stellenbosch, Stellenbosch 7600, South Africa ${ }^{1}$; Dipartimento di Science Technologie Agro-Alimentari Microbiologiche, Università degli Studi del Molise, 86100 Campobasso, Italy ${ }^{2}$ and Institute of Food Research, Department of Microbiology, Reading Laboratory, Reading RG6 2EF, United Kingdom ${ }^{3}$

\begin{abstract}
Wine strains belonging to the genus Leuconostoc were classified as Leuconostoc oenos by Garvie in 1967, and this name was confirmed on the Approved Lists of Bacterial Names in 1980. L. oenos is distinguished from other Leuconostoc spp. by its growth in acidic media, by its requirement for a growth factor in tomato juice, and by a number of carbohydrate fermentation characteristics. In addition, the results of a total soluble cell protein analysis, an electrophoretic analysis of NAD-dependent D-(-)-lactate dehydrogenase, 6-phosphogluconate dehydrogenase, and alcohol dehydrogenase, and an analysis of cross-reactivity with anti-glucose-6-phosphate dehydrogenase and anti-NAD-dependent $\mathrm{D}-(-)$-lactate dehydrogenase performed with other Leuconostoc spp. clearly indicated that $L$. oenos should be distinguished from the other Leuconostoc species. Phylogenetic studies, in particular $16 \mathrm{~S}$ and $23 \mathrm{~S}$ rRNA sequencing studies, have revealed that $L$. oenos represents a distinct subline that is separate from other Leuconostoc spp. and lactic acid bacteria. In view of the phenotypic and phylogenetic distinctiveness of $L$. oenos, we propose that this species should be assigned to a new genus as Oenococcus oeni [corrig.] gen. nov., comb. nov. The type strain of $O$. oeni is NCDO 1674 (= ATCC 23179).
\end{abstract}

At the present time the genus Leuconostoc consists of the type species, Leuconostoc mesenteroides, and the following eight other species: Leuconostoc oenos, Leuconostoc pseudomesenteroides, Leuconostoc lactis, Leuconostoc citreum, Leuconostoc gelidum, Leuconostoc carnosum, Leuconostoc fallax, and Leuconostoc argentinum $(2,5,11,17,19,20)$. L. amelibiosum is now considered a subjective synonym of L. citreum (21), whereas organisms formerly designated Leuconostoc cremoris and Leuconostoc dextranicum are now classified as subspecies of L. mesenteroides (10). Leuconostoc paramesenteroides has recently been assigned to the new genus Weissella, as Weissella paramesenteroides (1).

$L$. oenos is the only acidophilic member of the genus $L e u$ conostoc and occurs naturally in wine and related habitats $(6$, $11,12)$. Strains of $L$. oenos are distinguished from the other Leuconostoc spp. by their growth at an initial $\mathrm{pH}$ of 4.8 and in media containing $10 \%(\mathrm{vol} / \mathrm{vol})$ ethanol, by their requirement for a tomato juice growth factor (most strains), and by their lack of NAD-dependent glucose-6-phosphate dehydrogenase (11). The electrophoretic mobilities of NAD-dependent D-(-)lactate dehydrogenase, 6-phosphogluconate dehydrogenase, and alcohol dehydrogenase also clearly distinguish $L$. oenos from the other Leuconostoc spp. (3, 7, 11, 12). Furthermore, antisera prepared from $L$. oenos exhibit no cross-reactivity with L. lactis anti-glucose-6-phosphate dehydrogenase and antiNAD-dependent $\mathrm{D}-(-)$-lactate dehydrogenase $(14)$ and $L$. mesenteroides subsp. mesenteroides anti-glucose-6-phosphate dehydrogenase (13). L. oenos is also distinguished from other Leuconostoc spp. by its total soluble cell protein pattern (4).

Further evidence that $L$. oenos is a distinct taxon comes from genotypic investigations. Chromosomal DNA-DNA pairing has been used extensively to determine the genetic interrelationships of members of the genus Leuconostoc $(4,5,8,15,19)$. Although $L$. oenos has been shown to be a distinct species by this approach, more significant are the very low levels of DNA

\footnotetext{
* Corresponding author.
}

homology detected between this species and other members of the genus (Table 1). Such low levels of homology indicate that there is a very distinct genomic relationship between $L$. oenos and the nonacidophilic species of the genus. DNA-rRNA hybridization analyses $(9,19)$ and rRNA sequence analyses $(16$, 22) have also revealed the genotypic distinctness of $L$. oenos. In particular, 16S rRNA sequencing $(16,22)$ and, more recently, 23S rRNA (18) sequencing have revealed that the leuconostocs form three distinct lines of descent (viz., Leuconostoc sensu stricto, including $L$. mesenteroides; the $L$. paramesenteroides group of species, including some atypical lactobacilli; and $L$. oenos) (Fig. 1).

Yang and Woese (22) and Martinez-Murcia et al. (16-18) have shown that $L$. oenos is unusual in that it exhibits a relatively long rRNA branch. It has been suggested by Yang and Woese (22) that this characteristic, together with the phenotypic peculiarities of $L$. oenos and its negligible levels of DNA homology with other Leuconostoc spp., indicates that $L$. oenos is a fast-evolving organism. However, irrespective of whether $L$. oenos is a fast-evolving organism, it is clear from the results of comparative $16 \mathrm{~S}$ and $23 \mathrm{~S}$ rRNA sequencing analyses that this species forms a distinct line within the so-called "Leuconostoc branch" that is worthy of separate generic status (18). Recently, a taxonomic reorganization of the leuconostocs was initiated with the introduction of the genus Weissella for $L$. paramesenteroides and its close relatives (1). On the basis of the phenotypic and phylogenetic evidence mentioned above, we propose that $L$. oenos should be reclassified in a new genus, Oenococcus, thereby completing the necessary taxonomic revision of the Leuconostoc branch of the lactic acid bacteria. It should be noted that when this taxon was assigned to the genus Leuconostoc by Garvie (6), the specific epithet was incorrectly presented as oenos, which is the nominative form of the noun; however, the genitive is required. The specific epithet was also incorrectly Latinized as a nominative; the correct Latinized form is oinus. We therefore propose that the specific epithet oenos should be changed to the correct Latin genitive form, oeni. 
TABLE 1. Levels of DNA-DNA homology for leuconostocs ${ }^{a}$

\begin{tabular}{|c|c|c|c|c|c|}
\hline \multirow[b]{2}{*}{ Species or subspecies } & \multicolumn{5}{|c|}{$\%$ Homology with $\left[{ }^{3} \mathrm{H}\right]$ DNA from: } \\
\hline & $\begin{array}{l}\text { L. mesenteroides } \\
\text { subsp. mesenteroides }\end{array}$ & L. pseudomesenteroides & L. paramesenteroides & L. lactis & L. carnosum \\
\hline L. mesenteroides subsp. mesenteroides & $73-108$ & $24-63$ & $7-18$ & $7-38$ & $1-17$ \\
\hline L. mesenteroides subsp. cremoris & $66-106$ & $20-50$ & $5-10$ & $5-35$ & $4-10$ \\
\hline L. mesenteroides subsp. dextranicum & $84-110$ & $38-49$ & $5-19$ & $6-35$ & $5-8$ \\
\hline L. pseudomesenteroides & $18-48$ & $70-100$ & $9-22$ & $13-36$ & $\mathrm{ND}^{b}$ \\
\hline L. paramesenteroides & $6-19$ & $7-30$ & $82-100$ & $8-14$ & $0-3$ \\
\hline L. lactis & $16-49$ & $23-61$ & $0-25$ & $74-100$ & $7-22$ \\
\hline L. amelibiosum & 39 & 34 & 22 & 32 & $\mathrm{ND}$ \\
\hline L. carnosum & $19-32$ & ND & $0-6$ & $0-25$ & $78-116$ \\
\hline L. gelidum & $9-31$ & ND & $0-3$ & $0-10$ & $3-21$ \\
\hline L. citreum & $21-30$ & $27-56$ & $10-20$ & 23 & ND \\
\hline L. oenos & $8-15$ & $5-10$ & $5-7$ & $3-11$ & ND \\
\hline L. fallax & $28-41$ & ND & 25 & $\mathrm{ND}$ & ND \\
\hline L. argentinum & 9 & ND & ND & $35-39$ & ND \\
\hline
\end{tabular}

${ }^{a}$ Data from references $2,4,5,11,15,17,19$, and 20 .

${ }^{b} \mathrm{ND}$, no data.

Description of Oenococcus gen. nov. Oenococcus (Oe.no. coc'cus. Gr. n. oinos, wine; Gr. masc. n. kokkus, berry, little round thing; N.L. masc. n. Oenococcus, little round thing from wine). Gram-positive, nonmotile, asporogenous, ellipsoidal to spherical cells usually occur in pairs or chains. Cell morphology varies from strain to strain and is influenced by the growth medium. Chemoorganotrophic. Facultatively anaerobic. Catalase negative. No cytochromes are present. Nonproteolytic.
Nitrates are not reduced. Nonhemolytic. Indole is not formed. Acidophilic; prefers an initial growth $\mathrm{pH}$ of 4.8. Grows in media supplemented with $10 \%$ (vol/vol) ethanol. Growth in broth is slow and usually uniform. Surface growth is enhanced by incubation in a $10 \% \mathrm{CO}_{2}$ atmosphere. Colonies usually develop only after 5 days and are less than $1 \mathrm{~mm}$ in diameter. Grows at temperatures between 20 and $30^{\circ} \mathrm{C}$. Requires a rich medium containing complex growth factors and amino acids.

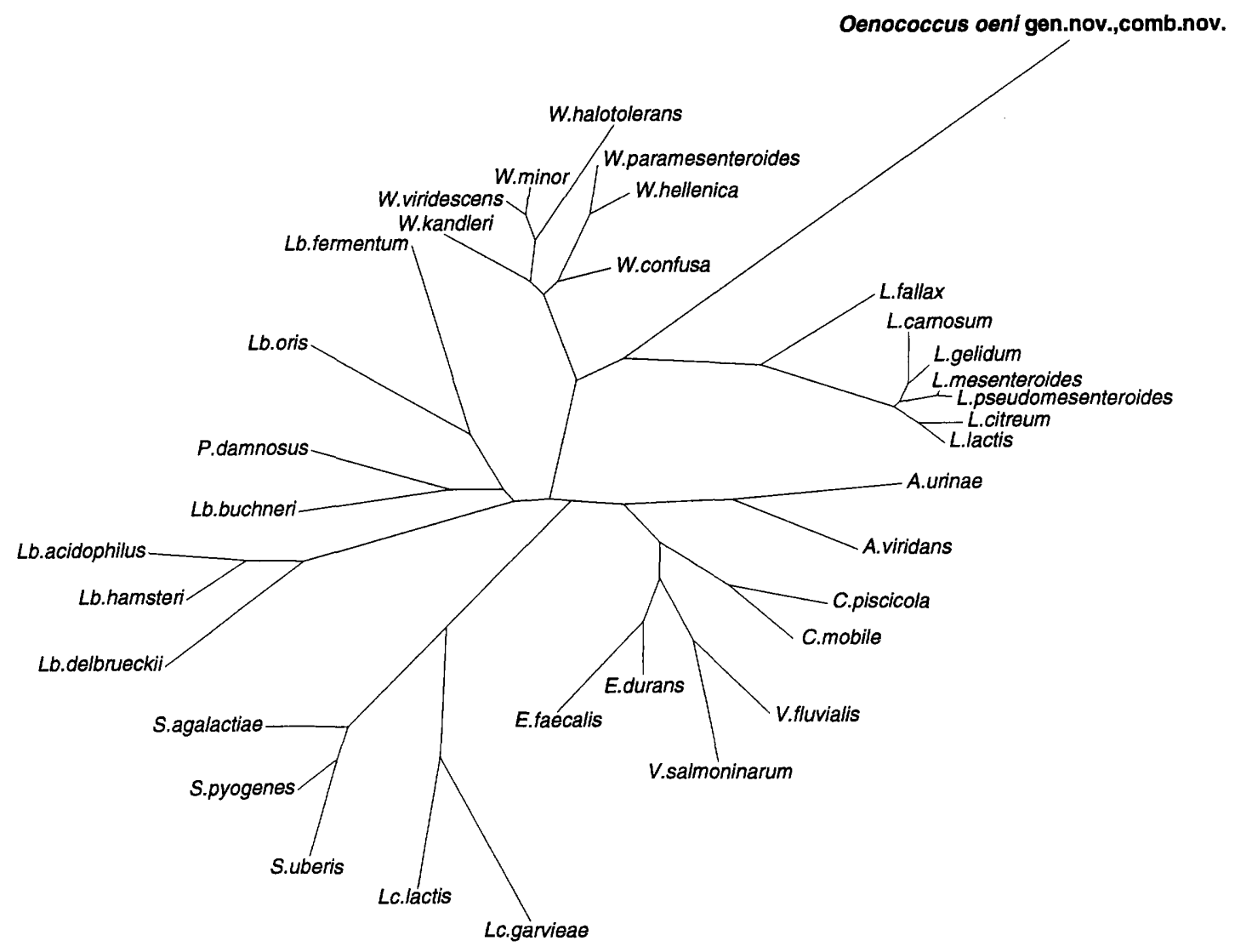

FIG. 1. Unrooted phylogenetic tree showing the relationship of $O$. oeni to Leuconostoc spp. and "lactic acid bacteria" based on $16 \mathrm{~S}$ rRNA sequences. Abbreviations: W., Weissella; Lb., Lactobacillus; L., Leuconostoc; P., Pediococcus; A., Aerococcus; C., Camobacterium; E., Enterococcus; S., Streptococcus; V., Vibrio; Lc., Lactococcus. 
Grows only in the presence of tomato juice, grape juice, pantothenic acid, or $4^{\prime}-O$ - $(\beta$-glucopyranosyl $)$-D-pantothenic acid. Glucose is fermented to equal amounts of D-(-)-lactic acid, $\mathrm{CO}_{2}$, and ethanol or acetate via a pathway that is not yet fully elucidated. L-Malate is decarboxylated to $\mathrm{L}-(+)$-lactate in the presence of a fermentable carbohydrate. NAD-dependent glucose-6-phosphate dehydrogenase is not present. The amino acid sequence of the interpeptide bridge of the cell wall peptidoglycan is of the L-Lys-L-Ala-L-Ser or L-Lys-L-Ser-L-Ser type. The DNA base composition is 37 to $42 \mathrm{~mol} \% \mathrm{G}+\mathrm{C}$ (as determined by the thermal denaturation method). The type species is Oenococcus oeni (6) [corrig.] comb. nov. (Leuconostoc oenos).

Description of Oenococcus oeni [corrig.] comb. nov. Oenococcus oeni (oe'ni. Gr. gen. n. oinou, of wine; N.L. gen. n. oeni, of wine). Acidophilic; grows in grape must and wine at $\mathrm{pH} 3.5$ to 3.8. Prefers an initial growth $\mathrm{pH}$ of 4.8. Growth is not inhibited in the presence of $10 \%$ ( $\mathrm{vol} / \mathrm{vol})$ ethanol. The optimum growth temperature is $22^{\circ} \mathrm{C}$. Growth at $15^{\circ} \mathrm{C}$ is slow. Requires a rich growth medium supplemented with grape juice, tomato juice, pantothenic acid, or a glucose derivative of pantothenate. Converts L-malate to $\mathrm{L}-(+)$-lactate and $\mathrm{CO}_{2}$ in the presence of a fermentable carbohydrate. Glucose is fermented to D- $(-)$-lactic acid, $\mathrm{CO}_{2}$, and ethanol or acetate. Metabolically inactive; ferments only a few carbohydrates. Prefers fructose and usually ferments trehalose. In grape must or wine, pentose sugars (arabinose or xylose) are fermented before glucose, resulting in diauxic growth. Variable reactions for arabinose, cellobiose, galactose, mannose, melibiose, salicin, and xylose fermentation. Sucrose, lactose, maltose, mannitol, and raffinose are not fermented. Esculin is hydrolyzed. Arginine is hydrolyzed by certain strains, but only in wine or related habitats. Certain strains ferment citrate in the presence of a fermentable carbohydrate, but this characteristic is often lost when strains are subcultured. Glucose-6-phosphate dehydrogenase activity is observed only in the presence of NADP. NADdependent $\mathrm{D}-(-)$-lactate dehydrogenase migrates slowly, and at least nine electrophoretically different NAD-dependent D(-)-lactate dehydrogenase bands have been observed. Growth in yeast glucose milk is unusual, but if it occurs, acid and gas are not produced. Certain strains produce extracellular polysaccharides in medium supplemented with grape juice. The amino acid sequence of the interpeptide bridge of the cell wall peptidoglycan is L-Lys-L-Ala-L-Ser or L-Lys-L-Ser-L-Ser. The $\mathrm{G}+\mathrm{C}$ content of the DNA is 38 to $42 \mathrm{~mol} \%$ (as determined by the thermal denaturation method). The type strain is NCDO 1674 (= ATCC 23179). Isolated from wine.

We are grateful to T. O. MacAdoo (Virginia Polytechnic Institute and State University, Blacksburg) for advice concerning the derivation of the generic name.

M.D.C. is grateful to the Ministry of Agriculture, Fisheries and Food for support.

\section{REFERENCES}

1. Collins, M. D., J. Samelis, J. Metaxopoulos, and S. Wallbanks. 1993. Taxonomic studies on some leuconostoc-like organisms from fermented sau- sages: description of a new genus Weissella for the Leuconostoc paramesenteroides group of species. J. Appl. Bacteriol. 75:595-603.

2. Dicks, L. M. T., L. Fantuzzi, F. C. Gonzalez, M. Du Toit, and F. Dellaglio. 1993. Leuconostoc argentinum sp. nov., isolated from Argentine raw milk. Int. J. Syst. Bacteriol. 43:347-351.

3. Dicks, L. M. T., and H. J. J. van Vuuren. 1990. Differentiation of Leuconostoc species by nicotinamide adenine dinucleotide-dependent $\mathrm{D}(-)$-lactic dehydrogenase profiles. FEMS Microbiol. Lett. 67:9-14.

4. Dicks, L. M. T., H. J. J. van Vuuren, and F. Dellaglio. 1990. Taxonomy of Leuconostoc species, particularly Leuconostoc oenos, as revealed by numerical analysis of total soluble cell protein patterns, DNA base compositions, and DNA-DNA hybridizations. Int. J. Syst. Bacteriol. 40:83-91.

5. Farrow, J. A. E., R. R. Facklam, and M. D. Collins. 1989. Nucleic acid homologies of some vancomycin-resistant leuconostocs and description of Leuconostoc citreum sp. nov. and Leuconostoc pseudomesenteroides sp. nov. Int. J. Syst. Bacteriol. 39:279-283.

6. Garvie, E. I. 1967. Leuconostoc oenos sp. nov. J. Gen. Microbiol. 48:431-438.

7. Garvie, E. I. 1969. Lactic dehydrogenases of strains of the genus Leuconostoc. J. Gen. Microbiol. 58:85-94.

8. Garvie, E. I. 1976. Hybridization between the deoxyribonucleic acids of some strains of heterofermentative lactic acid bacteria. Int. J. Syst. Bacteriol. 26:116-122.

9. Garvie, E. I. 1981. Sub-divisions within the genus Leuconostoc as shown by RNA/DNA hybridization. J. Gen. Microbiol. 127:209-212.

10. Garvie, E. I. 1983. Leuconostoc mesenteroides subsp. cremoris (Knudsen and Sorensen) comb. nov. and Leuconostoc mesenteroides subsp. dextranicum (Beijerinck) comb. nov. Int. J. Syst. Bacteriol. 33:118-119.

11. Garvie, E. I. 1986. Genus Leuconostoc, p. 1071-1075. In P. H. A. Sneath, N. S. Mair, M. E. Sharpe, and J. G. Holt (ed.), Bergey's manual of systematic bacteriology, vol. 2. The Williams \& Wilkins Co., Baltimore.

12. Garvie, E. I., and J. A. E. Farrow. 1980. The differentiation of Leuconostoc oenos from non-acidophilic species of Leuconostoc, and the identification of five strains from the American Type Culture Collection. Am. J. Enol. Vitic. 31:154-157.

13. Gasser, F., and M. Hontebeyrie. 1977. Immunological relationships of glucose-6-phosphate dehydrogenase of Leuconostoc mesenteroides NCDO 768 (= ATCC 12291). Int. J. Syst. Bacteriol. 27:6-8.

14. Hontebeyrie, M., and F. Gasser. 1975. Comparative immunological relationships of two distinct sets of isofunctional dehydrogenases in the genus Leuconostoc. Int. J. Syst. Bacteriol. 25:1-6.

15. Hontebeyrie, M., and F. Gasser. 1977. Deoxyribonucleic acid homologies in the genus Leuconostoc. Int. J. Syst. Bacteriol. 27:9-14.

16. Martinez-Murcia, A. J., and M. D. Collins. 1990. A phylogenetic analysis of the genus Leuconostoc based on reverse transcriptase sequencing of $16 \mathrm{~S}$ rRNA. FEMS Microbiol. Lett. 70:73-84.

17. Martinez-Murcia, A. J., and M. D. Collins. 1991. A phylogenetic analysis of an atypical leuconostoc: description of Leuconostoc fallax sp. nov. FEMS Microbiol. Lett. 82:55-60.

18. Martinez-Murcia, A. J., N. M. Harland, and M. D. Collins. 1993. Phylogenetic analysis of some leuconostocs and related organisms as determined from large-subunit rRNA gene sequences: assessment of congruence of small- and large-subunit rRNA derived trees. J. Appl. Bacteriol. 74:532-541.

19. Schillinger, U, W. Holzapfel, and O. Kandler. 1989. Nucleic acid hybridization studies on Leuconostoc and heterofermentative lactobacilli and description of Leuconostoc amelibiosum sp. nov. Syst. Appl. Microbiol. 12:48-55.

20. Shaw, B. G., and C. D. Harding. 1989. Leuconostoc gelidum sp. nov. and Leuconostoc carnosum sp. nov. from chill-stored meats. Int. J. Syst. Bacteriol. 39:217-223.

21. Takahashi, M., S. Okada, T. Uchimura, and M. Kozaki. 1992. Leuconostoc amelibiosum Schillinger, Holzapfel, and Kandler 1989 is a later subjective synonym of Leuconostoc citreum Farrow, Facklam, and Collins 1989. Int. J. Syst. Bacteriol. 42:649-651.

22. Yang, D., and C. R. Woese. 1989. Phylogenetic structure of the "Leuconostocs": an interesting case of a rapidly evolving organism. Syst. Appl. Microbiol. 12:145-149. 